\title{
Role of Interactive Multimedia in Environment Awareness
}

\author{
Imad Kamil Al Jadawi ${ }^{\mathrm{a}}$ and Vikas Rao Naidu ${ }^{\mathrm{a}}$
}

\begin{abstract}
Role of media in Environment Awareness is very significant. These days, social media has become one of the most common platforms to spread awareness on various aspects of environment. Then it can be about the climatic changes or it could be about the ecosystem of the country, people must be aware about the habitat, in which they are living and nurturing. The Ministry of Environment and Climate affairs, Oman, plays a vital role in this. It is responsible for weather monitoring and forecast apart from study of various nature reserves and animals which are becoming extinct slowly. This paper will evaluate various readily available means in order to raise awareness among the public. The result will be helpful to draw a framework with the help of which we can develop an appropriate system by using some multimedia tools. Apart from this, this paper will have review of some existing projects and literatures in the same area.Based on the findings, authors will be suggesting the development of mobile based application for regular updates on environment and its assets.
\end{abstract}

Keywords: Interactive media; Mobile Application; Environment Awareness; Educational videos; Smart technology

\begin{abstract}
Introduction
The Environment is one the most important aspects that we feel that every human being should be aware of. Particularly at this current time when Global warming has been effecting the world we live in. We found that it is very important that were all aware of the importance of taking care of the environment. We have also found out the Omani government take precautions about the environment we live in and taking care of it as well. Public awareness is something that they care deeply about and we came to a conclusion that this is a perfect topic to pursue.
\end{abstract}

The Ministry of Environment and Climate Affairs was established on 9 September 2007 by Royal Decree No. (90/2007) after the environmental march went through several organizational and structural stages. It starts with the establishment of the Office of the Advisor for Conservation of the Environment in 1974 and its most important functions was the establishment and development of the project of reintroduction of the Arabian Oryx into their natural habitats.

The Ministry of Environment and Climate Affairs as one of the government authorities is responsible for formulating plans and programs for protection of the environment and conservation of its natural resources through application of its policy to ensure safety of the environment, combat pollution and maintain the various ecosystems within the framework of the basic objectives of the sustainable development, as well as protection of wildlife, conservation of nature, preservation and sustainable use of resources. In addition to monitoring and assessment of climate change in coordination with the competent authorities to avoid many of the potential impacts of climate change on the natural, economic and social systems so as to be prepared to manage the risks of climate change by taking necessary actions, preparation of national strategies to mitigate greenhouse gas emissions and to adapt to these effects so as to confront the potential risks in this regard.

Unfortunately, till this day the ministry has little involvement went it comes to awareness videos. That is why we have done many researches and found the inspiration to encourage us to work on a project for them on videos that could impact society

After much research, we have found out that the best way for people to capture information is through videos. Research has found that videos have a bigger impact on taking in information then reading, listening and pictures. So we have decided to use videos as our media source to education people on Environment Awareness.

\section{LITERATURE STUDY}

Literature review is the search of information that has a relation to the research of the project. It provides the reader with information and concepts of given topics within the project report.

The first literature referred was an essential tutorial book that gives an in-depth guide to using Final Cut Pro X. The book will help give us the ability to master the tools of the software. As well as the characteristics of the software that makes it unique. This book will help in the editing process of the video, as well effects and subtitling. [1]

Another website provides necessary tutorials about Final Cut Pro. It provides step to steps instruction of how to use the software. This tutorial will be very beneficial when working on the video. The tutorial will be used side by siding during the editing process of the project. [2]

Authors also referred an article providing idea with a step to step guide to making promotional videos. It is written by an experienced video producer. The article is dived into a few steps: Strategic Planning, Pre-Production, Production, Post-Production and Distributing \& Marketing. This article will help in understanding the fundamentals of promotional videos will guide us through process of filing and editing. [3]

The next literature provides an instruction on how promotional videos are made. This video will help while filming. It is a short 5-minute video that we can watch over and over again as a reminder during the implantation of the project. [3]

Another resource provides an insight to filmmaking and editing from an artist point of view. It helps to bring out the creativity in the video with learning about visualization, colors and angles. [4]

Authors referred another resource that provides an in-depth insight to Environmental Awareness. It provides necessary information about the issues we are currently faces, and how to overcome them. This reference helps significantly in understanding the environment in general in order to develop the most significant Environmental videos possible. [6]

The authors also referred a handbook that provides idea about DSLR filming. The reference is a great guide on how to use DSLR cameras in terms of filming. This reference will help significantly when it comes to shooting. [11] 
The methodology that we have chosen to peruse for the project is the Spiral Methodology. We have found that it is more suitable for large projects. This methodology rotates between all development phases, as well as the design phase and implementation phase. The Spiral Methodology is divided into four crucial stages:

Planning Phase: This phase is where all the studies, requirements are collected in order to begin the next the phase. Risk Analysis Phase: This phase is conducted to classify any potential risk that might occur during the development of the project.

Engineering Phase: This phase is where the development of the actual project takes place.

Evaluation Phase: This phase will be based on the client's evaluation of the project. The client's feedback will determine whether to enter another development cycle for improvement and changes or give the project an approval

We have chosen Spiral Model for our work due to the fact that it has the most flexible approach between the SDLC models. With this approach, we can easily edit, add and delete ideas, plans and work in every phase without making changes in the diagram. We can reduce the risks with using a systematic approach as well

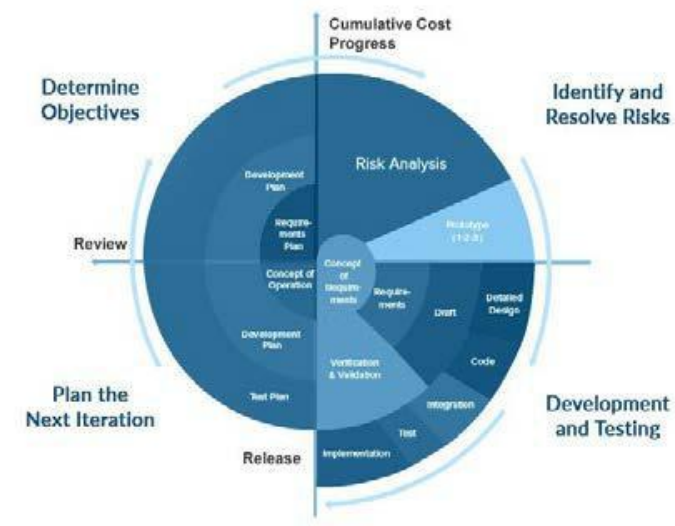

Fig 1. Spiral Model

\section{DATA COLLECTION}

Interviews are an excessive way to father information for a particular project. The power of interviews comes from the fact that we manage to meet and discuss with people and that gives a more profound understanding about their views and compassions about a particular topic. We view Interviews as a primary source for our data collection to develop this project.

Questionnaires are a primary method to collect information about projects. We have found that spreading questionnaires out will give us an insight on things that people may not want to discuss in person. It gives us a better understanding on topics that we ask ourselves regularly while developing this Project.

The question below demonstrates how people feel about people's awareness of the importance of the environment, while many people believe that most people are aware. The majority of the people do believe that people are indeed not aware of it.

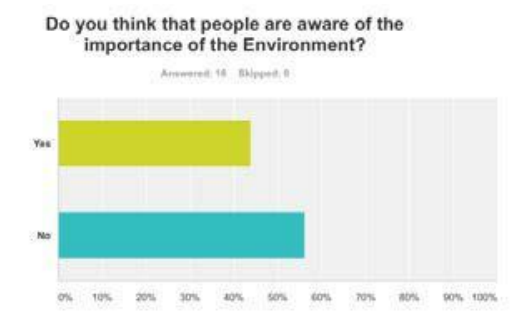

\section{Fig 2. Questionnaire Analysis 1}

The following question demonstrates how people feel that the best medium to register information is videos. Most People agree but some strongly agree and few disagree on this statement.
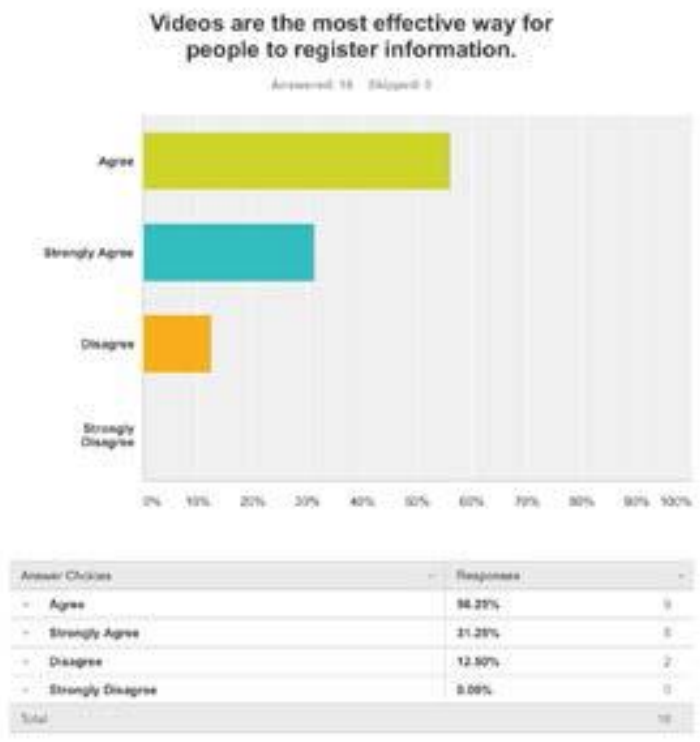

Fig 3. Questionnaire Analysis 2

This question gives us an understanding about what people feel is most important issue with the Environment. While a few people think that Public Awareness, Climate Change \& Nature conservation are an important issue. $43 \%$ of the people think that Pollution is the most important issue with the Environment

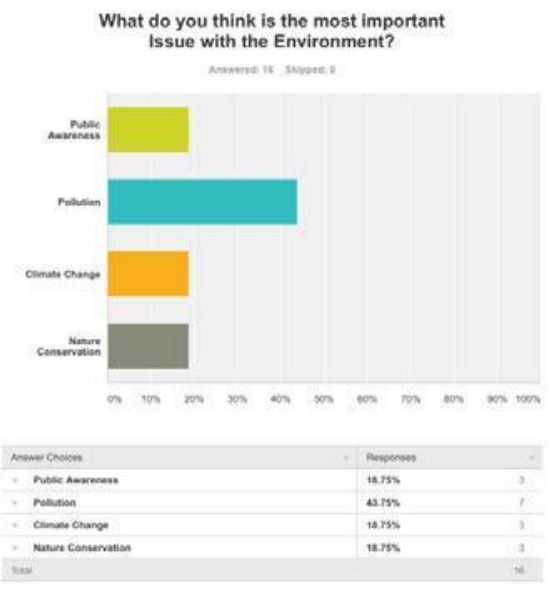

Fig 4. Questionnaire Analysis 3

In the following Question, we have asked people give their opinion on how healthy they think the environment is. $31.25 \%$ of the people think it's good. Almost $13 \%$ of the people think it's excellent. Almost $60 \%$ think it's fair, and none think that it Poor. 


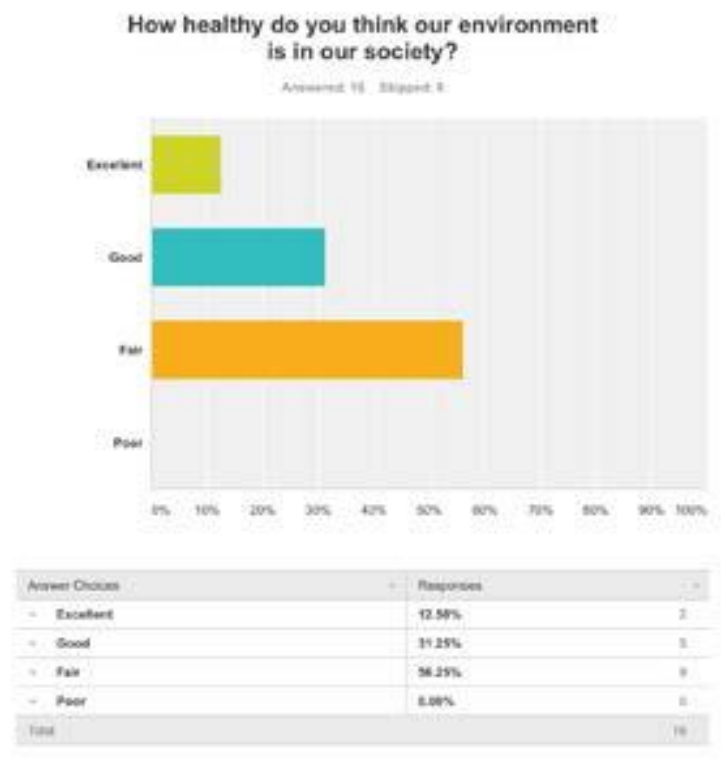

Fig 5. Questionnaire Analysis 4

The following Question Shows that everyone feel that promotion plays a huge rule in living in a healthier environment.

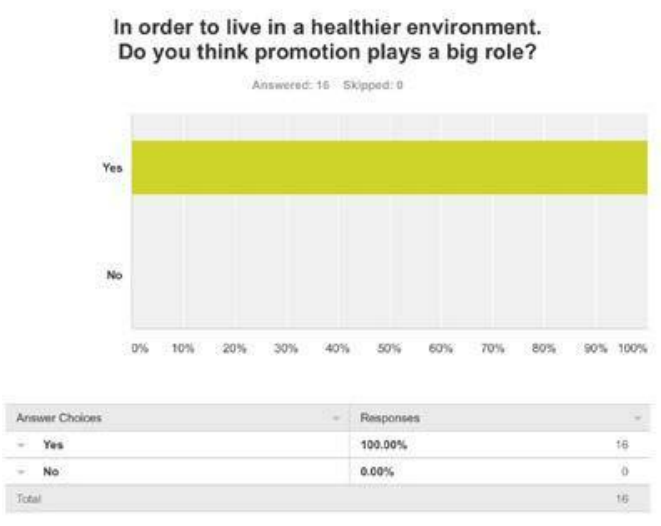

Fig 6. Questionnaire Analysis 4

\section{DIAGRAMS FOR PROPOSED SYSTEM}

a. Initial Block Diagram:

The initial block diagram shown in Fig 7 shows the proposed system flow. There will be a home screen from where other pages could be navigated. Videos will not be embedded in the application; rather they will be linked to the online resources due to optimized size of the final application.

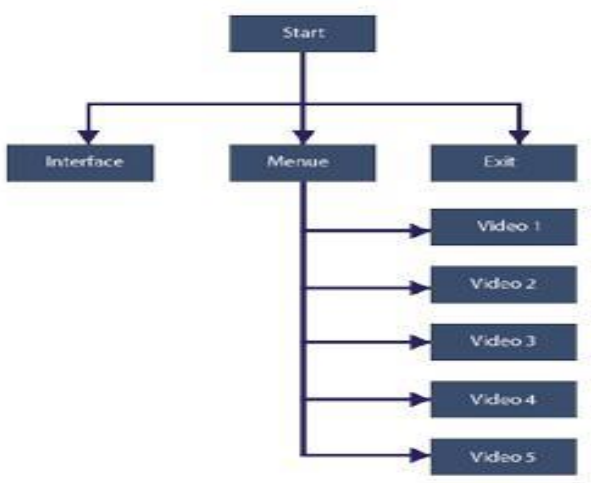

Fig 7. Block Diagram

Screen Prototypes:

Following diagrams shows the initial prototypes which are proposed based on findings of this research. This application could be implemented both on KIOSK as well as mobile platform and the basic layout is shown in Fig 8 and Fig 9 respectively.
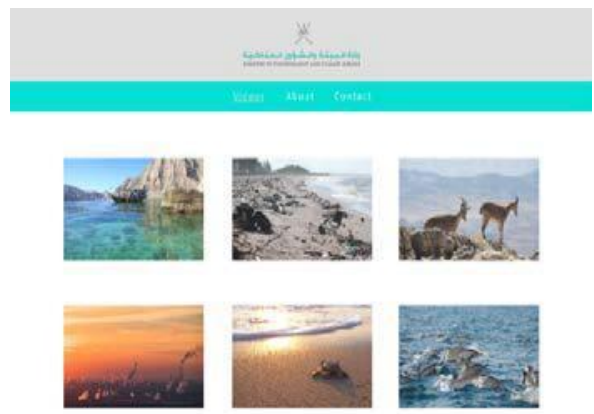

Fig 8. Video Page for KIOSK
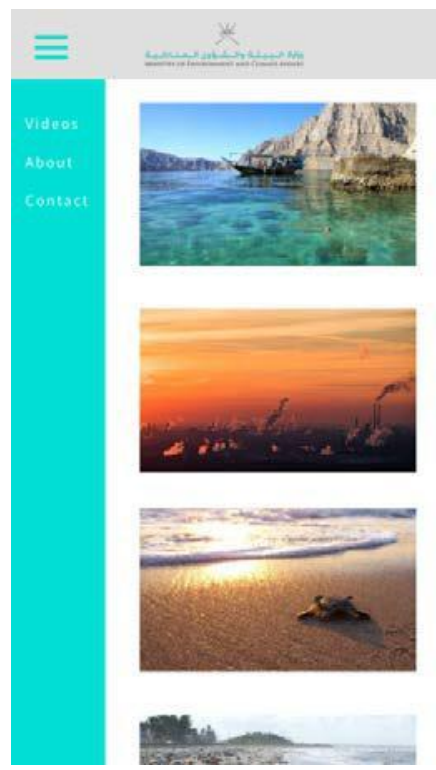

Fig 9. Video Page for Mobile

\section{CONCLUSION}

In conclusion, we find that Environmental Issues are extremely important to society. This project will hopefully encourage people to be more aware of the environment. We would like to give the Ministry and the viewers the best possible series of videos to will hopefully be highly influential, and impact society as a whole.

\section{ACKNOWLEDGEMENT}


I would like to express my thanks to all who have assisted me in completing my project planning. I would like to thank my supervisor Mr. Vikas Rao for being a great mentor in this process, and working with me hand to hand in order to create the best possible research. Last but not the least many thanks goes to my friends.

\section{References}

Wohl, Michael, 2012. Apple Pro Training Series: Final Cut Pro X Advanced Editing. 1st ed. California: Peachpit Press.

"Final Cut Pro - Online Courses, Classes, Training, Tutorials on Lynda", Lynda.com - from LinkedIn, 2017. [Online]. Available: https://www.lynda.com/Final-Cut-Pro-trainingtutorials/201-0.html.

[Accessed: 28- Dec- 2016].

"5 Steps: How To Make A Promotional Video, Step-By-Step Guide - Reel Marketer", Reel Marketer, 2017. [Online]. Available: http://www.reelmarketer.com/how-to-make-apromotional-video/.

[Accessed: 29- Dec- 2016].

"the art of filmmaking and editing. - YouTube", Youtube.com,

2017. [Online]. Available: https://www.youtube.com/results?search_query=the+art+of $+f$ ilmmak ing+and+editing. [Accessed: 01- Jan- 2017].

"How To Make A Promotional Video", YouTube, 2017. [Online]. Available: https://www.youtube.com/watch?v=VZzBym2_X0w.

[Accessed: 07- Jan- 2017].

B. Kingsolver, A novel, 1st ed. London: Faber and Faber, 2013.
H. Kerzner, Project management, 1st ed. Hoboken, NJ: Wiley, 2006.

P. Baguley, Project management, 1st ed. London: Teach Yourself, 2003.

K. Heldman, Project management JumpStart, 1st ed. San Francisco, Calif.: SYBEX, 2003.

J. Creswell and V. Plano Clark, Designing and conducting mixed methods research, 1st ed. Thousand Oaks: Sage, 2009.

B.Andersson, The DSLR filmmaker's handbook, $1^{\text {st }}$ ed.Hoboken, New Jersey: Sybex, 2015. 